\title{
DEVELOPMENT AND METHODS OF VALIDATION FOR MESUREMENT OF PESTICIDES IN MUSCLE TISSUE USING GAS CHROMATOGRAPHY BASED MODIFIED ANALYTICAL QUECHERS APPROACH
}

\author{
AHMAD, Y. H. ${ }^{1 *}-$ KHULOD, I. H. ${ }^{2}$ \\ ${ }^{1}$ Department of Microbiology, College of Veterinary Medicine, University of Sulaimani, New \\ Sulaimani, Street 27, P.C 46001, Sulaymaniyah, Northern Iraq \\ ${ }^{2}$ Department of Food Science and Human Nutrition, College of Agricultural Sciences, \\ University of Sulaimani, Street 27, P.C 46001, Sulaymaniyah, Northern Iraq \\ (phone: +964-771-948-1949) \\ *Corresponding author \\ e-mail:ahmad.hamadamin@univsul.edu.iq; phone: +964-771-666-2829
}

(Received $5^{\text {th }}$ Aug 2019; accepted 25 $5^{\text {th }}$ Nov 2019)

\begin{abstract}
A multi residue detection method for the quantification of six wide spectrum non-polar pesticides in the muscle of cattle, sheep, and goats was developed in this study. The method was based on a modified QuEChERS procedure adapted to gas chromatography coupled with mass spectrometry (GCMS). About 150 meat samples were analyzed to detect and quantify pyrethroids (PYRs) including cypermethrin (CMT), deltamethrin (DMT), organochlorines (OCs) including hexachlorobenzene (HCB), $\alpha$-hexachlorocyclohexane $(\alpha-\mathrm{HCH})$ and organophosphates (OPs), such as chlorpyrifos (CPS) and fenitrothion (FTN). Subsequently, the effects of boiling $\left(100{ }^{\circ} \mathrm{C}, 30 \mathrm{~min}\right)$ and broiling $\left(176{ }^{\circ} \mathrm{C}, 20 \mathrm{~min}\right)$ on the level of pesticides in the meat were tested. Acceptable responses of analytes were obtained at validation levels of 0.01 to $0.1 \mathrm{mg} / \mathrm{kg}$. The linear coefficients $\left(\mathrm{r}^{2}\right)$ were $\geq 0.9997$, and limits of detection (LOD) and limit of quantification (LOQ) values ranged from 0.004 to 0.014 and 0.012 to $0.043 \mathrm{mg} / \mathrm{kg}$ respectively. Satisfactory recovery (79.2 to $104.3 \%$ ) was obtained for all spiked levels with acceptable relative standard deviation (RSD) $(\leq 14.6 \%)$. The dominant compound found in cattle muscle was hexachlorobenzene (HCB), while deltamethrin (DMT) was the most dominant pesticide in sheep and goats samples. Boiling technique reduced meat pesticides significantly $(\mathrm{P}<0.05)$, whereas the effects of broiling were questionable. The validation results confirmed that the proposed method can be utilized as a dependable screening apparatus and analytical procedure for quantitative determination of studied pesticides in animal tissues.
\end{abstract}

Keywords: pyrethroids, organochlorines, organophosphoruses, boiling, broiling

Abbreviations: GC: Gas Chromatography; MS: Mass spectrometry; QuEChERS: Quick, Easy, Cheap, Effective, Rugged, and Safe; PYRs: Pyrethroids; OCs: Organochlorines; OPs: Organophosphoruses; DMT: Deltamethrin; CMT: Cypermethrin; HCB: Hexachlorobenzene; Alpha-HCH: $\alpha-$ hexachlorocyclohexane; CPS: Chlorpyrifos; FTN: Fenitrothion; LOD: Limit of detection; LOQ: Limit of quantification; RSD: Relative standard deviation; $r^{2}$ : linear coefficients; SPE: Solid phase extraction; SPA: Primary Secondary amines; C18: Octadecylsilane; $\mathrm{ACN}$ : Acetonitrile; $\mathrm{MgSO}_{4}$ : Magnesium sulphate; NaCl: Sodium chloride; d-SPE: Dispersive solid phase extraction; MS/MS: Tandem mass spectrometry; ECD: Electron capture detection; n: number of samples; mm: millimeter; $\mu \mathrm{m}$ : Micromillipore; cm: centimeter; WSS: Working standard solution; MMC: Matrix-matched calibration; ANOVA: Analysis of Variance; LLE: Liquid-liquid extraction; LLP: Liquid-liquid partitioning; MRLs: Maximum residue limits

\section{Introduction}

The innovation of pesticides has played a vital role in the development of agriculture and veterinary science, and they have been irreplaceable until now. In veterinary 
medicine, pesticides are used for the treatment of external parasites, while in agriculture, they are used intensively for prevention and treatment of crops pre and postharvests (Lainsbury, 2019). Their extensive use of pesticides has resulted in their widespread distribution and transfer to animals (MacBean, 2015). These contamination routes can lead to bioaccumulation of pesticides in food products of animal origin such as meat, fat, and milk, finally leading to pesticides being transferred to humans via the food chain (Castillo et al., 2012).

Pyrethroids (PYRs), organochlorines (OCs), and organophosphorus (OPs) pesticides are effective against variety of pests, have been widely used around the world (Castillo et al., 2012). Their extreme stability, low volatility, and probable indiscriminate use in the past have led to their high persistence in the environment and in organisms after exposure (Lainsbury, 2019). Among these groups of pesticides, non-polar pesticides are more hazardous than polar pesticides because they have a strong tendency to be stored in body tissues and only small amounts are excreted through kidneys (MacBean, 2015). Ingestion of tiny doses of pesticides daily or weekly may cause life-long illnesses, neurological problems, cancers, anemia, and cardiovascular illnesses in humans (MacBean, 2015).

Several methods have been used to quantify of pesticide residues in animal derived foods, but the key technique is: firstly, how several pesticides residues can be efficiently extracted from the complex matrixes; secondly, how cleaning up is performed to minimise matters co-extracts; thirdly, what analytical method should be proposed for accurate quantification.

QuEChERS (quick, easy, cheap, effective, rugged and safe) extraction technique is the most popular extraction method (Anastassiades et al., 2003). The method is based on acetonitrile extraction followed by a cleanup, using dispersive solid phase extraction (d-SPE) with a primary secondary amine (PSA), octadecylsilane (C18). At first, the method was simply used for determination of specified groups of pesticide in fruit and vegetables. Later, it was validated for a variety of pesticide groups in high fat content foods, such as meat and internal organs (Meligy et al., 2019), chicken eggs (Nardelli et al., 2018) and fish (Sahu and Nelapati, 2018).

Among chromatographic techniques, GC is the most frequently used technique (Vitha, 2016). The GC has been used for detection of multi-residues in liquid matrices (Schettgen et al., 2016), and complex tissue matrices (Letta and Attah, 2013). Variety of detectors have been used with GC, such as tandem MS (MS/MS) (Arioli et al., 2019), mass spectrometry (MS) (Meligy et al., 2019) electron capture detection (ECD) (Dimitrova et al., 2018). The most preferred by laboratories is GC, due to its high sensitivity suitability for halogen and non-halogen containing compounds (Grimalt and Dehouck, 2016). MS suffers more from sample matrix interferences than other detection methods (Meligy et al., 2019); this has made it difficult to optimize a method which reliably screens several groups of pesticides in a complex tissue.

Moreover, risk assessments of residues in meat are based on the level of residues in uncooked meat, even though a large proportion of consumed meat is either cooked or processed before consumption. In order to thoroughly assess the risks to consumers of pesticide residues, the effects of heat treatment on the residues should be considered (Kiranmayi et al., 2016; Yun-Sang et al., 2016). Studies have shown that heat treatment can cause considerable reduction of pesticide residues in food commodities (Witczak, 2009; Muthukumar et al., 2010). The presence of residues above the permissible levels is a major barrier in the approval of meats, as well as posing domestic public health 
issue. Therefore, to confirm the safety of meats, the levels of pesticides in meat should be determined professionally before and after heat treatments.

To date, no enough study performed to assess the effect of boiling at $100{ }^{\circ} \mathrm{C}$ for $30 \mathrm{~min}$ and broiling at $176^{\circ} \mathrm{C}$ for $20 \mathrm{~min}$ on studied pesticides in meat tissues which are the most commonly used temperature (Goldwyn and Blonder, 2016).

The aim of this study was to optimize GC-MS and to adapt a modified QuEChERS method for detection and quantification of six pesticides belonging to three classes, by optimising experimental conditions in both sample preparation and chromatography using an acceptable validation procedure. With this technique the levels of the six pesticide residues in tissues and effects of boiling $\left(100{ }^{\circ} \mathrm{C}, 30 \mathrm{~min}\right)$ and broiling $\left(176{ }^{\circ} \mathrm{C}, 20 \mathrm{~min}\right)$ on the pesticides residual levels were measured.

\section{Material and methods}

\section{Sample collection}

Meat samples $(n=150)$ were randomly collected from adult cattle $(n=50)$, sheep $(\mathrm{n}=50)$, and goat $(\mathrm{n}=50)$ carcasses at the Sulaimaniyah slaughterhouse. Each sample was sliced into three equivalent portions of $50 \mathrm{~g}(150 \times 3)$. The first portion $(\mathrm{n}=150)$ was straightforwardly prepared for extraction and analysis. The second $(n=150)$ and third $(\mathrm{n}=150)$ portions were boiled $\left(100{ }^{\circ} \mathrm{C}, 30 \mathrm{~min}\right)$ and broiled $\left(176^{\circ} \mathrm{C}, 20 \mathrm{~min}\right)$ respectively. Blank meat samples were acquired from animals free from all pesticides obtained formally from the Brazilian Agricultural Research Cooperation Center. Samples collection and the study performed in Sulaimaniyah city/Kurdistan region of Iraq.

The blank samples were tested to confirm that they were free from the studied pesticides. Then aliquot of samples for selectivity study, the rest portion spiked and used for recovery, matrix matched standards calibration, and sensitivity studies.

\section{Chemical and apparatus}

All solvents were of pesticide-residue grade. Pesticides standards of cypermethrin (CMT)(94\%), deltamethrin (DMT)(99\%), hexachlorobenzene (HCB)(98\%), $\alpha-$ hexachlorocyclohexane $(\alpha-\mathrm{HCH})(98 \%)$, chlorpyrifos (CPS)(96\%) and fenitrothion (FTN)(95.5\%) were obtained from Dr. Ehrenerstorfer TM (Augsberg, Germany). Acetonitrile (ACN) (99.5\%), acetic acid (99.9\%) primary secondary amine (PSA) $40 \mu \mathrm{m}$ particle size, octadecylsilane $(\mathrm{C} 18,50 \mu \mathrm{m})$, sodium chloride $(\mathrm{NaCl})$, and anhydrous magnesium sulphate $\left(\mathrm{MgSO}_{4}\right)$ were obtained from Merck Ltd. Syringe filters $(0.45 \mu \mathrm{m})$, and capillary columns, $30 \mathrm{~m} \mathrm{DB}-5$, with an internal diameter of $0.25 \mathrm{~mm}$ and thickness of $0.1 \mu \mathrm{m}$ were purchased from Supelco Analytical Co., UK.

\section{GC-MS system}

The pesticides' concentrations were detected by gas chromatography, along with mass spectrometry. This was performed using a QP GC-MS gas chromatograph from Shimadzu (Kyoto, Japan), equipped with a mass-selective detector and capillary column of a $30 \mathrm{~m}$ DB-5, with $0.25 \mathrm{~mm}$ internal diameter and $0.1 \mu \mathrm{m}$ film thicknesses. The injector, interface, and ion source temperatures were $250{ }^{\circ} \mathrm{C}$, and splitless injection $(1.0 \mathrm{~min})$ was performed using helium as the carrier gas with a flow rate of $0.75 \mathrm{~mL} / \mathrm{min}$. The oven temperature was set to increase at a pace of $4{ }^{\circ} \mathrm{C} / \mathrm{min}$ from 
$120{ }^{\circ} \mathrm{C}$ to $190{ }^{\circ} \mathrm{C}$. Next, the temperature was increased from $32{ }^{\circ} \mathrm{C} / \mathrm{min}$ to $270{ }^{\circ} \mathrm{C}$, and held for $4 \mathrm{~min}$. The mass spectrometer was operated with scan mode, put between $\mathrm{m} / \mathrm{z}$ 45 and $\mathrm{m} / z, 475$ Daltons, which can detect analytes in a solvent to a limit of $1.0 \mathrm{mg} / \mathrm{kg}$. The injection volume was $50 \mu \mathrm{L}$ with a splitless injection mode.

\section{Heat treatment}

Samples were made into small patties of about $1.5 \mathrm{~cm}$ thickness. About 150 samples were placed separately into low-density water-impermeable polyethylene bags and cooked in boiling water $\left(100{ }^{\circ} \mathrm{C}, 30 \mathrm{~min}\right)$ using a water bath (Memmert W200, Germany). Similarly, the other 150 samples were put in a glass bowl and broiled in a preheated air oven (Memmert 93/42 EEC, Germany), at $176^{\circ} \mathrm{C}$ for $20 \mathrm{~min}$, being turned over every $5 \mathrm{~min}$. During the experiment, the water bath and oven temperature were monitored with a thermometer and oven thermometer gauge respectively.

\section{Method of validation}

Validation method for this study was carried out according to the internationally accepted SANTE/11813/2017 criteria, i.e., selectivity, recovery percentages, precision, linearity, and sensitivity. Method selectivity was tested by injection of 10 independent meat sample extracts into GC-MS. The absence of interfering peaks above a signal-tonoise ratio of 3 at the retention time window of interest was checked for each analyte. The target retention times of the analytes were identified by separately injecting analytical standards $(10 \mathrm{mg} / \mathrm{L})$ into the GC-MS apparatus. Multi-standard solutions were injected in to the GC-MS to check maximum retention time tolerance range $( \pm 0.2$ min), and improve analytical validation. Recovery was determined by comparing the obtained concentrations with the same concentrations of the pesticides prepared in the dissolvent. The inter-day precisions ( 3 replicates in 3 successive days) were determined by analyzing all spiked levels through the injection of multi-standard solutions, containing six analytes, at concentrations of $0.010,0.025,0.050$, and $0.100 \mathrm{mg} / \mathrm{kg}$ for control matrices. Since a different maximum residue limit (MRL) has been established for each analyte in meat, $0.01-0.1 \mathrm{mg} / \mathrm{kg}$ of standard solutions were spiked into blank matrices to obtain the highest method reliability during screening. The linearity test in meat was carried out by injecting six matrix-matched standards for calibration studies. Limits of detection (LOD) and quantitation (LOQ) were determined based on a signalto-noise ratio, and concentrations showing peak intensity of signal-to-noise ratio of 3 and 10 were designated as LOD and LOQ, respectively.

\section{Matrix-matched calibration (MMC)}

According to SANTE/11813/2017 criteria, matrix constituents negatively influence the quantitation of target analyses in GC-MS analyses and may increase or decrease the analytical signals. Hence, matrix-matching (standards added to blank extracts) is performed mainly to minimize matrix effects. For the preparation of analytical MMC curves, individual stock solutions of HCB, $\alpha-\mathrm{HCH}, \mathrm{FTN}, \mathrm{CPS}, \mathrm{CMT}$, and DMT were prepared in acetonitrile in Pyrex glass vials at a concentration of $100 \mathrm{mg} / \mathrm{L}$ and stored at $-20{ }^{\circ} \mathrm{C}$ in dark amber bottles. Working standard solutions (WSS) was prepared at a concentration of $50 \mathrm{mg} / \mathrm{L}$ by diluting stock solution in acetonitrile. Matrix-matched calibration standards was prepared just before injection by diluting the working solutions and spiked into extracted blank samples to obtain concentrations of 0.010 , 
$0.025,0.050,0.100,0.200$ and $0.500 \mathrm{mg} / \mathrm{kg}$. The MMC curves for each compound were built, and coefficients $\left(\mathrm{r}^{2}\right)$ of calibration curves were used to assess linearity.

\section{Preparation of meat samples}

The extraction and cleanup procedures performed based on original QuEChERS method (Anastassiades et al., 2003) and (Lehotay et al., 2005) with few modifications. Meat samples were thawed at $4{ }^{\circ} \mathrm{C}$ overnight prior to use. Blank meat samples $(2 \mathrm{~g})$ were homogenised and fortified with $20 \mu \mathrm{L}$ of each 10,5, 2.5 and $1 \mathrm{mg} / \mathrm{L}$ of multistandards solution (including the six pesticides) to prepare samples of $0.1,0.05$, 0.025 and $0.01 \mathrm{mg} / \mathrm{kg}$. These were mixed with the matrix for 2 min and left to interact for $30 \mathrm{~min}$. The, blended meat samples were transferred to a $50 \mathrm{~mL}$ Falcon tube. Next, $4 \mathrm{~mL}$ of $\mathrm{ACN}$ (containing $1 \%$ acetic acid), $1.6 \mathrm{~g}$ of anhydrous $\mathrm{MgSO}_{4}$, and $0.4 \mathrm{~g}$ of $\mathrm{NaCl}$ were added and the mixture was agitated in a vortex mixer for $1 \mathrm{~min}$. The mixture was centrifuged at $3000 \mathrm{rpm}$ for $3 \mathrm{~min}$ to separate the phases (liquid-liquid partition). The supernatant, corresponding to the organic solvent ACN, was transferred to a tube containing $70 \mathrm{mg}$ of $\mathrm{C} 18,70 \mathrm{mg}$ of the adsorbent PSA and $150 \mathrm{mg}$ of $\mathrm{MgSO}_{4}$. The tube was shaken by hand for half a minute, and centrifuged at $4000 \mathrm{rpm}$ for $1 \mathrm{~min}$. The supernatant was filtered by syringe filter $(0.45 \mu \mathrm{m})$ to remove the excess of colouring materials. The filtered supernatant was subjected to evaporation under a stream of nitrogen (Hopkinton, LabX, USA) at $45{ }^{\circ} \mathrm{C}$ and stored at $4{ }^{\circ} \mathrm{C}$. The solutions were transferred to an autosampler vial and injected into the GC-MS under optimum conditions.

\section{Data processing and statistical analysis}

Matrix-matched standards data were subjected to the computer programs of Excel (Analysis ToolPak, Regression) for sensitivity and F test. The obtained real samples data (concentration data for each pesticide and animal species, heat treatment data subjected to the Analysis of Variance (One-way ANOVA, Post Hoc = Duncan, using SPSS software (Version 18.0), multiple ranges used to significantly compare means $(\mathrm{p}<0.05)$.

\section{Results and discussion}

\section{Development of QuEChERS method}

Traditionally, non-polar pesticides have been extracted by liquid-liquid extraction (LLE) and solid-phase extraction (SPE). These extraction procedures are not recommended as they are time-consuming, multi-step procedures and need large amounts of organic solvents (Kang et al., 2011). By contrast, the use of the QuEChERS technique has significantly reduced the demerits of traditional extraction procedures because of its small scale LLE and d-SPE (Lehotay et al., 2005). Hence, in the present study, the original QuEChERS method was considered, which was proposed by Anastassiades et al. (2003) and Lehotay et al. (2005). In the first step of the test, the method of (Anastassiades et al., 2003) was applied, in which $10 \mathrm{~g}$ of the meat sample and $10 \mathrm{~mL}$ of $\mathrm{ACN}, 4 \mathrm{~g}$ of $\mathrm{MgSO}_{4}$, and $1 \mathrm{~g}$ of $\mathrm{NaCl}$ were used for liquid-liquid partitioning (LLP). For the second step (d- SPE), the method of Lehotay et al. (2005) was used, in which $50 \mathrm{mg}$ of C18, $50 \mathrm{mg}$ of PSA and $150 \mathrm{mg}$ of $\mathrm{MgSO}_{4}$ were added to the mixture. The method of Anastassiades et al. (2003) was used in the first step of the 
procedure because this method does not require buffers for the extraction of analytes. For the second step, the method of Lehotay et al. (2005) was used, because it provides better cleanup due to the use of a larger mass of PSA and the addition of C18. Unexpectedly, the obtained recovery values varied from 60 to $74 \%$, with high RSD values (>20\%). Hence, additional tests were carried out. In the second test, the QuEChERS method was modified. Meat samples ( $2 \mathrm{~g}$ ), $4 \mathrm{~mL}$ of $\mathrm{ACN}, 1.6 \mathrm{~g}$ of $\mathrm{MgSO}_{4}$, and $0.4 \mathrm{~g}$ of $\mathrm{NaCl}$ were used, as well as for the d-SPE, $70 \mathrm{mg}$ of PSA, $70 \mathrm{mg}$ of C18, and $150 \mathrm{mg}$ of $\mathrm{MgSO}_{4}$. The obtained recovery and RSD rates were satisfactory according to SANTE/11813/2017 (Table 1). Many parameters can influence the extraction efficiency, including the type of solvent, polarity, and cleanup sorbents including C18 and PSA (Okihashi et al., 2007). Hence, the second test, the ratio of ACN to sample weight was changed from1:1 to 1:2, and PSA and C18 were increased to $70 \mathrm{mg}$, and the quantity of $\mathrm{MgSO}_{4}$ held constant with additional one filtration step.

The extraction of pesticide residues depends on the polarity of pesticides and type of matrix contained pesticides (Peng et al., 2016). In this test, ACN was selected for extraction of pesticides because of its effectiveness in the extraction of polar and nonpolar pesticides from the diverse range of matrices. The cleanup step also improved by increasing PSA and C18 from 50 to to $70 \mathrm{mg}$. The PSA could effectively eliminate polar matrix components, such as organic acids, certain polar pigments, and sugars. The C18 also thoroughly removed fatty acids, which are considered the main co-extract of the non-polar pesticides in meat, among other components (Paramasivam et al., 2011). $\mathrm{MgSO}_{4}$ could also bind with organic acids, polar material and/or glucosides. The salt combination $\left(\mathrm{NaCl}, \mathrm{MgSO}_{4}\right)$ produced heat and forced the majority of co-extracts into the acetonitrile layer. The filtration step finally could totally remove the coloring materials in the solution, prompted cleanup and prepared the solution for injection.

In this study, cleaning up step was mostly considered to optimise and adapt the QuEChERS technique; firstly, to obtain acceptable recovery and, RSD, and to maximize extraction efficiency, and peak resolution; secondly, insufficient cleaning up of samples from the co-extractives in the extract causes deterioration of the GC system and precludes reliable results (Peng et al., 2016). Optimization of the chromatographic conditions was carried out to obtain a good compromise between low chromatographic times and suitable peak resolutions. Under the optimized chromatographic conditions, a satisfying separation was achieved with symmetrical and narrow peaks in the retention times between 2.93 and 9.75 min (Fig. 1A).

The extraction efficiency of the proposed method was assessed by spiking meat samples with multi pesticides at four concentrations level $(0.01,0.025,0.050$ and $0.1 \mathrm{mg} / \mathrm{kg}$ ). Good methodology efficiency was obtained in all concentrations regarding recovery percentages. To assess the possible existence of matrix effects, meat samples were extracted and spiked, and then they were compared with analytical standards at same concentrations. The calculations were performed using the peak areas and concluded that there were no significant differences between signal responses (ANOVA, $p>0.05$ ).

\section{Precision and recovery}

Recovery percentages were evaluated by comparing the concentrations of spiked samples, with the nominal fortification level. The recovery of each analyte was verified by calculating their average and put in compliance with the recovery range reported in SANTE/11813/2017. 


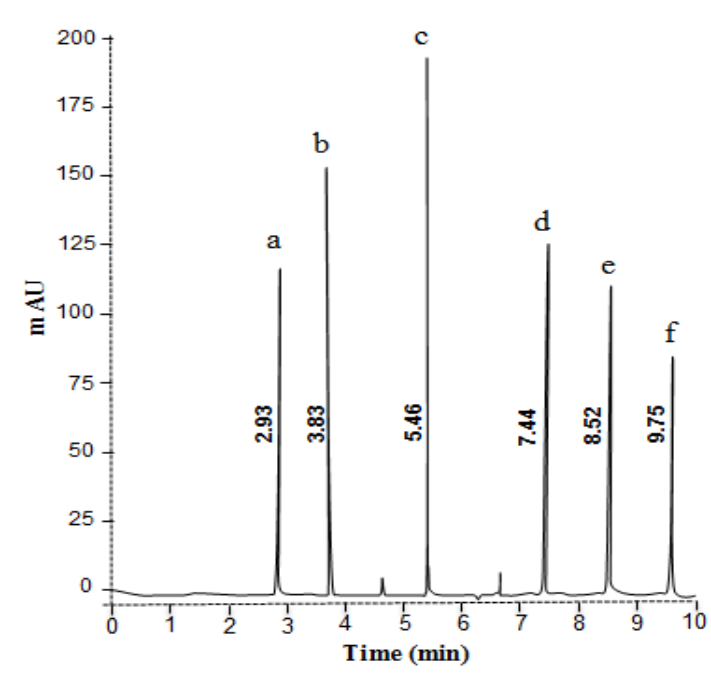

A

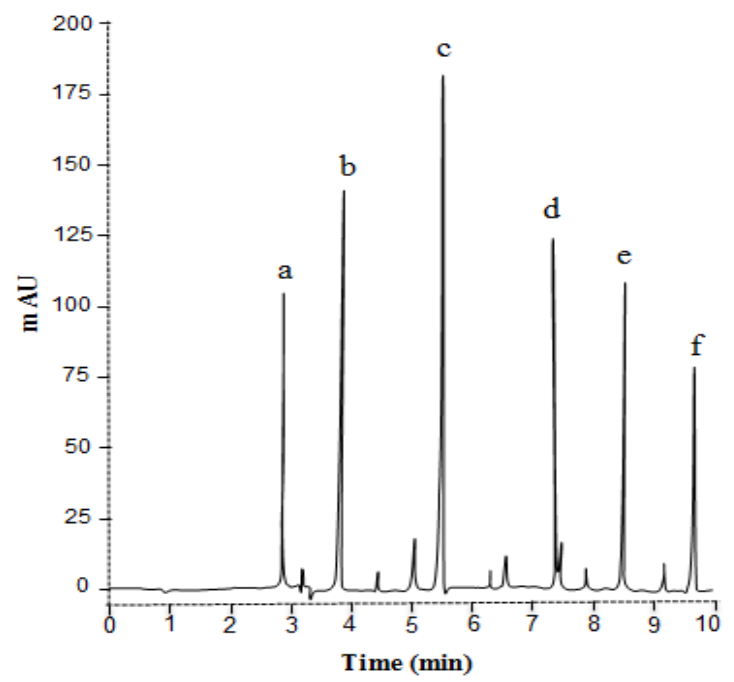

B

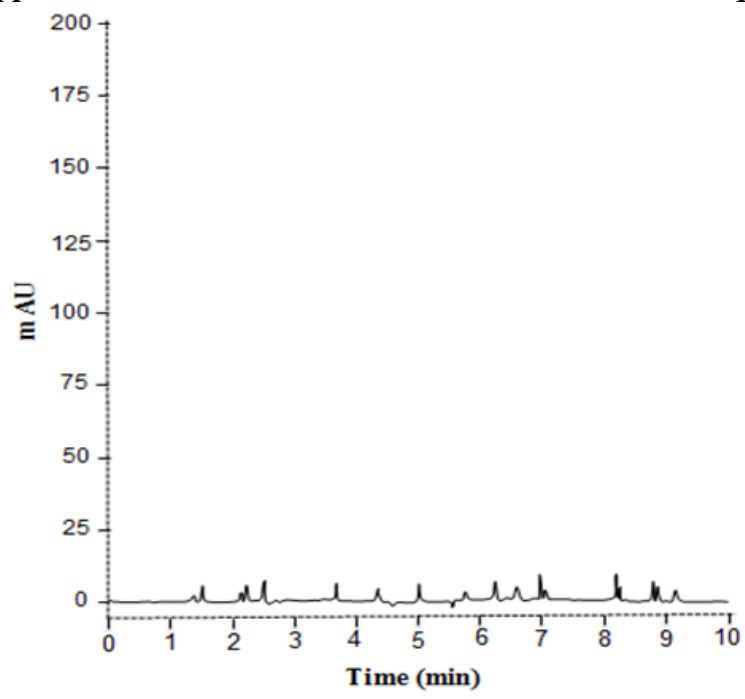

$\mathrm{C}$

Figure 1. GC chromatograms of QuEChERS method. A: A multi-standard solutions (10 mg/L). B: Spiked blank samples after extraction $(0.1 \mathrm{mg} / \mathrm{kg})$. C: Blank meat samples. a. Hexachlorobenzene; $b$. Hexachlorocyclohexane; c, Fenitrothion; $d$. Chlorpyrifos; $e$. Cypermethrin; f. Deltamethrin

The recovery values and RSDs were obtained using meat samples spiked with four different concentrations $(0.01,0.025,0.05$ and $0.1 \mathrm{mg} / \mathrm{kg})$. Acceptable recoveries $(79.2$ to $104.3 \%$ ) were obtained for all spiked levels, demonstrating that the matrix of meat samples was not affected by the extraction of the analytes (Table 1). The precision of the method was determined in two stages: repeatability (intra-day) and intermediate precision (inter-day). The intermediate precision was expressed by the RSD of the results of nine analyses performed on three different days $(n=3)$, three analyses/day, by the same instrument. The obtained RSD in this work was $0.32-14.6 \%$ for different spiked concentrations, which meets the recommendation of the SANTE/11813/2017 guidelines (RSD $\leq 20 \%$ ) (Table 1). These results demonstrate that the method possesses good accuracy and can be considered to be a useful tool for the screening of the six analytes in meat. Some of the tested compounds showed lower recovery than others. 
This might be due to some kind of interaction which could not be corrected with matrix matching, or the samples might have been decomposed in the processes of extraction, cleanup, or evaporation (Okihashi et al., 2007). High RDS in some analytes might be due to a high level of co-extracts that interfered in the GC system. By contrast, some showed low RDS, which could be due to ion speculation (Okihashi et al., 2007). The main analytical problem in chromatographic analysis has been reported to be the complexity of the matrix together with interfering co-extractive substances. These factors may deteriorate the chromatographic column (Frenich et al., 2006). Therefore, the analysis of three groups of pesticides in meat samples is recommended that samples should be cleaned up thoroughly prior extraction process.

Table 1. Recovery and relative standard deviations (RSD \%) in different spiked concentrations $(n=3)$

\begin{tabular}{c|c|c|c|c|c|c}
\hline Spiked matrix & \multicolumn{7}{|c}{ Recovery \pm RDS (\%) } \\
\hline Conc. (mg/kg) & CMT & DMT & HCB & $\alpha-H C H$ & CPS & FTN \\
0.01 & $79.2 \pm 7.4$ & $85.8 \pm 1.7$ & $85.8 \pm 13.09$ & $82.7 \pm 3.8$ & $88.3 \pm 13.3$ & $97.6 \pm 6.3$ \\
0.025 & $82.7 \pm 7$ & $88.9 \pm 1.8$ & $86.1 \pm 10.2$ & $104.3 \pm 4.6$ & $91.4 \pm 8.6$ & $96.28 \pm 3.1$ \\
0.05 & $86.8 \pm 4.1$ & $93.5 \pm 1.3$ & $88.6 \pm 14.6$ & $98.7 \pm 5.1$ & $92.1 \pm 9$ & $96.3 \pm 4.8$ \\
0.10 & $97.3 \pm 0.9$ & $98.1 \pm 0.32$ & $98.07 \pm 1.5$ & $97.5 \pm 3.1$ & $98.6 \pm 1.5$ & $99.6 \pm 0.6$ \\
\hline
\end{tabular}

RSD: Relative standard deviation, CMT: Cypermethrin, DMT: Deltamethrin, HCB: Hexachlorobenzene, $\alpha$-HCH: alpha-Hexachlorocyclohexane, CPS: Chlorpyrifos, FTN: Fenitrothion

\section{Linearity and limits of detection and quantification}

While, linearity can be tested using standard working solutions, in this study the spiked blank sample after extraction was used to correct matrix effects. The linearity was evaluated by constructing regression graphs at concentrations of $0.010,0.025$, $0.050,0.100,0.200$ and $0.500 \mathrm{mg} / \mathrm{kg}$. The acceptability of the regression model was also confirmed by using all the calibration datasets (six calibration points with three replicates at each calibration point). The regression was statistically analysed by the determination coefficients $\left(\mathrm{r}^{2}\right)$, and the homoscedasticity assumption was evaluated by plotting residue versus concentration. The coefficients $\left(r^{2}\right)$ were $\geq 0.9997$, and the residual plot showed that the errors were randomly distributed around the concentration axis. The $F$-test, performed according to the recommendation of the Analytical Methods Committee criteria reported by Johnson et al. (2010), and validated the linearity of a model for significance level of 0.05 (Analysis ToolPak, Regression). According to Kaonga et al. (2015), the response of the detector to any analysed pesticide by GC was found to be dependent on the studied matrix properties Therefore; the achieved slope $\left(r^{2}\right)$ values for the analytes were close to each other due to the similarity in the composition of the matrices.

Test sensitivity or matrix effects and fluctuation in baseline noise have a strong impact on LOD and LOQ values. For this reason, their validation under these conditions is mandatory. In this work, the LOD and LOQ values ranged from 0.004 to 0.014 and 0.012 to $0.043 \mathrm{mg} / \mathrm{kg}$ respectively (Table 2). The LOD and LOQ for all the studied compounds were lower than the maximum residue limits (MRLs) established by EU 396/2005 and EU No 149/2008. This suggests that the method can detect the studied pesticides at an adequately low level, which confirms its validity. The method described 
here provides higher sensitivity than methods used by other researchers for quantifying pesticides in meat such as, GC-MS (Meligy et al., 2019), GC-MS-MS (Meligy et al., 2019), and GC-ECD (Dimitrova et al., 2018). This aspect is the key-factor for evaluating analytical methods, because the lower the LOD values, the lower the probability of false negative results (Stefanelli et al., 2009).

Table 2. Linearity range, regression equation, coefficients, limits of detection and limit of quantification

\begin{tabular}{c|c|c|c|c|c}
\hline Pesticides & Linearity range & Regression equation & $\mathbf{r}^{2}$ & LOD $(\mathbf{m g} / \mathbf{k g})$ & $\mathbf{L O Q}(\mathbf{m g} / \mathbf{k g})$ \\
\hline CMT & $0.01-0.5$ & $\mathrm{y}=1102 \mathrm{x}+2010.9$ & 0.9998 & 0.014 & 0.043 \\
DMT & $0.01-0.5$ & $\mathrm{y}=820.48 \mathrm{x}+835.28$ & 0.9999 & 0.009 & 0.027 \\
HCB & $0.01-0.5$ & $\mathrm{y}=1120.2 \mathrm{x}+1060.5$ & 0.9999 & 0.006 & 0.019 \\
$\alpha-\mathrm{HCH}$ & $0.01-0.5$ & $\mathrm{y}=1442.3 \mathrm{x}+846.02$ & 0.9999 & 0.006 & 0.020 \\
CPS & $0.01-0.5$ & $\mathrm{y}=1195.5 \mathrm{x}+502.26$ & 0.9997 & 0.014 & 0.043 \\
FTN & $0.01-0.5$ & $\mathrm{y}=1900.6 \mathrm{x}+679.8$ & 0.9999 & 0.004 & 0.012 \\
\hline
\end{tabular}

$r^{2}$ : coefficient, LOD: limit of detection, LOQ: limit of quantification

\section{Real samples analysis}

In this work, the level of DMT in sheep samples was the highest $(0.210 \pm 0.010$ $\mathrm{mg} / \mathrm{kg})$, followed by HCB in cattle samples $(0.204 \pm 0.008 \mathrm{mg} / \mathrm{kg})$. The concentration of FTN presented the lowest residual in all the meat samples from cattle $(0.040 \pm 0.002$ $\mathrm{mg} / \mathrm{kg})$, sheep $(0.059 \pm 0.003 \mathrm{mg} / \mathrm{kg})$ and goats $(0.019 \pm 0.002 \mathrm{mg} / \mathrm{kg})($ Table 3$)$.

The level of DMT and CMT detected in sheep and goat meat were high and exceeded than the acceptable limits of DMT $(0.03 \mathrm{mg} / \mathrm{kg})$ and CMT $(0.05 \mathrm{mg} / \mathrm{kg})$ set by EU R No.396/2005. These results agreed with other studies that also detected a high level of DMT from sheep and goats' meat near Sulaimaniyah (Abdulrahman, 2016) and with another study (Khashan, 2016) that found high DMT levels in cattle meat in Baghdad. High levels of $\mathrm{HCB}$ and $\alpha-\mathrm{HCH}$ were also detected in cattle samples which exceed than the acceptable limits of $\mathrm{HCB}$ and $\alpha-\mathrm{HCH}(0.02 \mathrm{mg} / \mathrm{kg})$ set by EU R No.149/2008. The same result found in another research (Kiranmayi et al., 2016), which showed that the result is due to extreme use of these pesticides in agriculture.

The higher incidence of DMT, CMT, HCB and $\alpha-\mathrm{HCH}$ might be due to the extensive use of these pesticides in livestock and agriculture due to their wide spectrum of biological activity and high stability in the environment (MacBean, 2015). These pesticides are mostly used in Kurdistan and northern Iraq because they are legally allowed to use DMT and CMT to control ticks, flies, fleas, lice, and mites in animal, and to treat seasonal crops with $\mathrm{HCB}$ and $\alpha-\mathrm{HCH}$ for controlling fungal disease and mosquito and as an antifouling agent. The reason of finding high level of PYRs, OCs pesticide residues could be due to their rapid effects and low cost compared to OPs pesticides.

The OPs pesticides detected in meat samples in this study are CPS and FTN, which presented lower concentration residues than PYRs and OCPs in cattle, sheep and goat samples. The concentration of CPS residues found in cattle $(0.124 \mathrm{mg} / \mathrm{kg})$, sheep $(0.110 \mathrm{mg} / \mathrm{kg})$, and goat $(0.071 \mathrm{mg} / \mathrm{kg})$ samples were higher than acceptable limits $(0.05 \mathrm{mg} / \mathrm{kg})$ set by EU R No 396/2005. Moreover, the FTN residues in cattle $(0.04 \mathrm{mg} / \mathrm{kg})$ and goat $(0.019)$ samples were less than the acceptable limit $(0.05 \mathrm{mg} / \mathrm{kg})$ 
set by EU R No 396/2005 except sheep samples $(0.059 \mathrm{mg} / \mathrm{kg})$ which were almost about over the acceptable level. Low CPS levels also fund by Muhammad et al. (2010) and FTN have been found in buffalo and cattle grazing outdoor (Park et al., 2006). The low incidence of CPS and FTN could be due to low stability of the compounds in the environment and lower use by farmers due to their costs.

Statistically, there was a significant difference between animal species in terms of residual levels among all pesticides (ANOVA, $p<0.05$ ) except $\alpha-\mathrm{HCH}$ and CPS between cattle and sheep samples. In cattle samples, there was no significant difference between the CMT and DMT (ANOVA, $p>0.05$ ), the rest pesticides residual levels were different statistically (ANOVA, $p<0.05$ ). In sheep samples significant difference was noticed between all pesticides residual levels (ANOVA, $p<0.05$ ) except CMT and CPS. While, in goat samples no difference was presented between DMT, HCB and $\alpha-$ $\mathrm{HCH}$ (ANOVA, $p>0.05$ ), and no difference was also noticed between CMT and CPS.

Table 3. Mean residual levels of the studied pesticides in meat tissues

\begin{tabular}{c|c|c|c}
\hline Pesticides & $\begin{array}{c}\text { Fresh (cattle) samples } \\
(\mathbf{m g} / \mathbf{k g} \pm \mathbf{R S E})\end{array}$ & $\begin{array}{c}\text { Fresh (sheep) samples } \\
(\mathbf{m g} / \mathbf{k g} \pm \mathbf{R S E})\end{array}$ & $\begin{array}{c}\text { Fresh (goats) samples } \\
(\mathbf{m g} / \mathbf{k g} \pm \mathbf{R S E})\end{array}$ \\
\hline CMT & $0.060^{\mathrm{Ab}} \pm 0.004$ & $0.102^{\mathrm{Cb}} \pm 0.004$ & $0.076^{\mathrm{Bb}} \pm 0.003$ \\
DMT & $0.057^{\mathrm{Ab}} \pm 0.005$ & $0.210^{\mathrm{Ce}} \pm 0.010$ & $0.100^{\mathrm{Bc}} \pm 0.005$ \\
$\mathrm{HCB}$ & $0.204^{\mathrm{Ce}} \pm 0.008$ & $0.131^{\mathrm{Bc}} \pm 0.005$ & $0.091^{\mathrm{Ac}} \pm 0.004$ \\
$\alpha-\mathrm{HCH}$ & $0.152^{\mathrm{Bd}} \pm 0.009$ & $0.151^{\mathrm{Bd}} \pm 0.006$ & $0.090^{\mathrm{Ac}} \pm 0.005$ \\
CPS & $0.124^{\mathrm{Bc}} \pm 0.007$ & $0.110^{\mathrm{Bb}} \pm 0.004$ & $0.071^{\mathrm{Ab}} \pm 0.005$ \\
FTN & $0.040^{\mathrm{Ba}} \pm 0.002$ & $0.059^{\mathrm{Ca}} \pm 0.003$ & $0.019^{\mathrm{Aa}} \pm 0.002$ \\
\hline
\end{tabular}

Values in the "Fresh samples" column are presented as a mean of 50 samples \pm SEM (standard error of mean), statistical analysis by one-way ANOVA, post hoc $=$ Duncan

A, B, CDifferent superscript letters denote significant differences within row $(p \leq 0.05)$

a, b, c, d, e Different superscript letters denote significant differences within column $(p \leq 0.05)$

\section{Heat treatment}

As shown in Table 4, boiling at $100{ }^{\circ} \mathrm{C}$ for 30 min reduced the concentrations of the pesticides significantly (ANOVA, $p<0.05$ ) in cattle, sheep, and goat muscle tissues. On the other hand, the reduction in concentration of the studied pesticides after broiling at $176{ }^{\circ} \mathrm{C}$ for $20 \mathrm{~min}$ was questionable. The significant reduction of the six pesticides during boiling could be attributed to the volatility of these compounds and the elimination of these compounds due to fat rendering induced by exposure to high temperature for a long time, which does not happen in open heating treatments (Khan and Rahman, 2017).

In the boiling and broiling process, the most reduced pesticide group in cattle, sheep and goat samples was the PYRs including CMT and DMT (Table 4). Followed by OCs (HCB and $\alpha-\mathrm{HCH}$ ), and the least reduction of pesticides were OP pesticides including CPS and FTN (Table 4).

The dissipation percentages in both methods were higher for PYR and OC pesticides, when compared to OPs pesticides (Table 4). This might be due to the chemical and physical properties of these pesticides and variation in susceptibility to heat among the different chemical compounds in pesticides affected by boiling and broiling (Muthukumar et al., 2010). The reduction in level was almost similar between PYRs and OCs, whereas the reduction of OPs differed noticeably. However, there is no strong 
correlation between the physiochemical properties of PYRs and OCs. Since various parameters involving molecular weight, volatility (vapour pressure), hydrolysis rate, and water solubility affect the reduction rate, no conclusive statement can be made about the degree to each parameter to the loss of pesticides during boiling or broiling.

However, boiling at high temperatures is more advisable; it dissolves and washes away water-soluble vitamins and 60 to $70 \%$ of minerals (Yun-Sang et al., 2016). Although, effects of broiling process were less than boiling, it is still preferred to obtain the maximum nutritional values without sacrificing flavor by consumers. Hence, it is recommended that consumers might consume heat treated meat by boiling to avoid pesticide health issues, which could be better than tasty broiled meat contained higher pesticides residues.

Table 4. Effects of cooking methods on the concentration of pesticides ( $\mathrm{mg} / \mathrm{kg} \pm R S E)$

\begin{tabular}{|c|c|c|c|c|}
\hline Pesticides & Species & Raw meat & $\begin{array}{c}\text { Boiling at } 100{ }^{\circ} \mathrm{C} \text { for } \\
30 \mathrm{~min}\end{array}$ & $\begin{array}{c}\text { Broiling at } 176^{\circ} \mathrm{C} \text { for } \\
20 \mathrm{~min}\end{array}$ \\
\hline \multirow{3}{*}{ CMT } & Cattle & $0.060^{\mathrm{Bb}} \pm 0.004$ & $0.038^{\mathrm{Aa}} \pm 0.003$ & $0.051^{\mathrm{Bb}} \pm 0.003$ \\
\hline & Sheep & $0.102^{\mathrm{Cb}} \pm 0.004$ & $0.059^{\mathrm{Ab}} \pm 0.002$ & $0.086^{\mathrm{Bb}} \pm 0.003$ \\
\hline & Goat & $0.076^{\mathrm{Cb}} \pm 0.003$ & $0.048^{\mathrm{Ab}} \pm 0.003$ & $0.065^{\mathrm{Bb}} \pm 0.002$ \\
\hline \multirow{3}{*}{ DMT } & Cattle & $0.057^{\mathrm{Bb}} \pm 0.005$ & $0.036^{\mathrm{Aa}} \pm 0.003$ & $0.048^{\mathrm{Bb}} \pm 0.004$ \\
\hline & Sheep & $0.210^{\mathrm{Ce}} \pm 0.011$ & $0.134^{\mathrm{Ac}} \pm 0.007$ & $0.172^{\mathrm{Be}} \pm 0.009$ \\
\hline & Goat & $0.100^{\mathrm{Cc}} \pm 0.005$ & $0.065^{\mathrm{Ad}} \pm 0.004$ & $0.086^{\mathrm{Bc}} \pm 0.005$ \\
\hline \multirow{3}{*}{$\mathrm{HCB}$} & Cattle & $0.204^{\mathrm{Ce}} \pm 0.008$ & $0.139^{\mathrm{Ad}} \pm 0.005$ & $0.177^{\mathrm{Be}} \pm 0.007$ \\
\hline & Sheep & $0.131^{\mathrm{Cc}} \pm 0.005$ & $0.088^{\mathrm{Ax}} \pm 0.003$ & $0.114^{\mathrm{Bc}} \pm 0.004$ \\
\hline & Goat & $0.091^{\mathrm{Cc}} \pm 0.004$ & $0.057^{\mathrm{Ac}} \pm 0.002$ & $0.082^{\mathrm{Bc}} \pm 0.003$ \\
\hline \multirow{3}{*}{$\alpha-\mathrm{HCH}$} & Cattle & $0.152^{\mathrm{Bd}} \pm 0.009$ & $0.099^{\mathrm{Ac}} \pm 0.006$ & $0.135^{\mathrm{Bd}} \pm 0.008$ \\
\hline & Sheep & $0.151^{\mathrm{Cd}} \pm 0.006$ & $0.098^{\mathrm{Ad}} \pm 0.004$ & $0.130^{\mathrm{Bd}} \pm 0.006$ \\
\hline & Goat & $0.090^{\mathrm{Bc}} \pm 0.005$ & $0.058^{\mathrm{Ac}} \pm 0.003$ & $0.080^{\mathrm{Bc}} \pm 0.004$ \\
\hline \multirow{3}{*}{ CPS } & Cattle & $0.124^{\mathrm{Bc}} \pm 0.007$ & $0.087^{\mathrm{Ab}} \pm 0.005$ & $0.110^{\mathrm{Ac}} \pm 0.006$ \\
\hline & Sheep & $0.110^{\mathrm{Cb}} \pm 0.004$ & $0.082^{\mathrm{Ac}} \pm 0.003$ & $0.099^{\mathrm{Bb}} \pm 0.004$ \\
\hline & Goat & $0.071^{\mathrm{Bb}} \pm 0.005$ & $0.054^{\mathrm{Ac}} \pm 0.003$ & $0.064^{\mathrm{ABb}} \pm 0.004$ \\
\hline \multirow{3}{*}{ FTN } & Cattle & $0.040^{\mathrm{Ba}} \pm 0.002$ & $0.031^{\mathrm{Aa}} \pm 0.002$ & $0.036^{\mathrm{ABa}} \pm 0.002$ \\
\hline & Sheep & $0.059^{\mathrm{Ba}} \pm 0.003$ & $0.044^{\mathrm{Aa}} \pm 0.002$ & $0.054^{\mathrm{Ba}} \pm 0.003$ \\
\hline & Goat & $0.019^{\mathrm{av}} \pm 0.002$ & $0.015^{\mathrm{av}} \pm 0.002$ & $0.017^{\mathrm{av}} \pm 0.001$ \\
\hline
\end{tabular}

A, B, CDifferent superscript letters denote significant differences within a row $(p \leq 0.05)$

a, b, c, d, eDifferent superscript letters denote significant differences within each species, between each pesticide $(p<0.05)$

\section{Conclusion}

The goal of this study to develop a simple, accurate, and inexpensive method for the extraction and analysis of six pesticides from three different groups has been achieved. The method developed here can detect of pesticides residues in meat above the level of $0.01 \mathrm{mg} / \mathrm{kg}$. The optimization of chromatographic conditions in this work involved the use of few organic solvents, suitable sample preparation, proper clean up and ensuring good extraction efficiency and response sensitivity. Hence, GC-MS adapted to solid phase extraction, and QuEChERS preparation were successfully employed for the quantification of pesticides residues in animal tissues. All six commonly used pesticides 
were found in cattle, sheep and goat samples, and only FTN in cattle and goat samples was lower than MRLs. The process of boiling at $100{ }^{\circ} \mathrm{C}$ for $30 \mathrm{~min}$ destroyed pesticides significantly, but it cannot reduce the concentration to safe level or below the MRLs, if the residuals begin at high level. Therefore, it is suggested that farmers should use pesticides in recommended amount and butchers should also avoid slaughtering animals directly after treatment with insecticides. Finally, consumers might consume boiled meat and meat products instead of broiled.

Further research could be applied on a wide range of PYRs, OCs and OPs pesticides to strongly find the effects of heat treatment on pesticides regarding their properties such as molecular weight, volatility (vapor pressure), hydrolysis rate and solubility behavior. The use of modified QuEChERS method in this study, for extraction of destroyed pesticides and byproducts after heating and detection by GC could be another part of the next research.

Acknowledgments. The authors would like to thank Food Hygiene laboratory at the College of Veterinary Medicine/University of Sulaimani, for the opportunity to use their specific equipment.

\section{REFERENCES}

[1] Abdulrahman, P. (2016): Determination of a pyrethroid insecticide deltamethrin residues in sheep's and goat's meat in Sulaimaniya Province. - International Journal of Advanced Biological Research Sciences 3: 48-53.

[2] Anastassiades, M., Lehotay, S. J., Štajnbaher, D., Schenck, F. J. (2003): Fast and easy multiresidue method employing acetonitrile extraction/partitioning and "dispersive solidphase extraction" for the determination of pesticide residues in produce. - Journal of AOAC International 86: 412-431.

[3] Arioli, F., Ceriani, F., Nobile, M., Vigano, R., Besozzi, M., Panseri, S., Chiesa, L. M. (2019): Presence of organic halogenated compounds, organophosphorus insecticides and polycyclic aromatic hydrocarbons in meat of different game animal species from an Italian subalpine area. - Food Additives \& Contaminants: Part A 36: 1244-1252.

[4] Castillo, M., Carbonell, E., González, C., Miralles-Marco, A. (2012): Pesticide Residue Analysis in Animal Origin Food. - IntechOpen, London.

[5] Dimitrova, R. T., Stoykova, I. I., Yankovska-Stefanova, T. T., Yaneva, S. A., Stoyanchev, T. T. (2018): Development of analytical method for determination of organochlorine pesticides residues in meat by GC-ECD. - Revue Méd. Vét. 169: 77-86.

[6] Frenich, A. G., Vidal, J. M., Sicilia, A. C., Rodríguez, M. G., Bolanos, P. P. (2006): Multiresidue analysis of organochlorine and organophosphorus pesticides in muscle of chicken, pork and lamb by gas chromatography-triple quadrupole mass spectrometry. Analytica Chimica Acta 558: 42-52.

[7] Goldwyn, M., Blonder, G. (2016): Meathead: The Science of Great Barbecue and Grilling. - Houghton Mifflin Harcourt, New York.

[8] Grimalt, S. and Dehouck, P. (2016): Review of analytical methods for the determination of pesticide residues in grapes. - Journal of Chromatography A 1433: 1-23.

[9] Johnson, D., Lorenz, G., Studebaker, G., Hopkins, D. (2010): Ticks on Beef Cattle. Pest Management News. - University of Arkansas, University of Arkansas, USDA, and County Governments Cooperating, Carolina.

[10] Kang, S., Chang, N., Zhao, Y., Pan, C. (2011): Development of a method for the simultaneous determination of six sulfonylurea herbicides in wheat, rice, and corn by liquid chromatography-tandem mass spectrometry. - Journal of Agricultural and Food Chemistry 59: 9776-9781. 


$$
-287-
$$

[11] Kaonga, C. C., Takeda, K., Sakugawa, H. (2015): Diuron, Irgarol 1051 and Fenitrothion contamination for a river passing through an agricultural and urban area in Higashi Hiroshima City, Japan. - Sci Total Environ 15: 450-458.

[12] Khan, M. S., Rahman, M. S. (2017): Pesticide Residue in Foods: Sources, Management, and Control. - Springer International Publishing, Steinhausen.

[13] Khashan, H. T. (2016): Determination of pyrethroid insecticide deltamethrin residues in cattle meat in Baghdad Province/Al-Rusafa. - International Journal of Advance Research of Biological Sciences 3: 193-199.

[14] Kiranmayi, C. B., Krishnaiah, N., Kumar, M. M., Kumar, M. S., Subhashini, N., Rao, T. M. (2016): Multiresidue analysis of pesticides in beef and mutton samples and study on effect of cooking on residual levels of aldrin and dieldrin. - International Journal of Environmental Technology 5: 195-203.

[15] Lainsbury, M. (2019): The UK Pesticide Guide 2018. - British Crop Production Council, Hampshire.

[16] Lehotay, S. J., Maštovská, K., Yun, S. J. (2005): Evaluation of two fast and easy methods for pesticide residue analysis in fatty food matrixes. - Journal of AOAC International 88: 630-638.

[17] Letta, B. D., Attah, L. E. (2013): Residue levels of organochlorine pesticides in cattle meat and organs slaughtered in selected towns in West Shoa Zone, Ethiopia. - Journal of Environmental Science and Health, Part B 48: 23-32.

[18] MacBean, C. (2015): The Pesticide Manual. 15 ${ }^{\text {th }}$ Ed. - British Crop Protection Council, London.

[19] Meligy, A., Al-taher, A., Ismail, M., Al-naeem, A., El-bahr, S., El-ghareeb, W. (2019): Pesticides and toxic metals residues in muscle and liver tissues of sheep, cattle and dromedary camel in Saudi Arabia. - Slov Vet Res 56: 157-166.

[20] Muhammad, F., Akhtar, M., Rahman, Z., Farooq, H., Khaliq, T., Anwar, M. (2010): Multi-residue determination of pesticides in the meat of cattle in Faisalabad-Pakistan. Egyptian Academic Journal of Biological Sciences 2: 19-28.

[21] Muthukumar, M., Reddy, K. S., Reddy, C. N., Reddy, K. K., Reddy, A. G., Reddy, D. J., Kondaiah, N. (2010): Detection of cyclodiene pesticide residues in buffalo meat and effect of cooking on residual level of endosulfan. - Journal of Food Science and Technology 47: 325-329.

[22] Nardelli, V., Casamassima, F., Gesualdo, G., Li, D., Marchesiello, W. M., Nardiello, D., Quinto, M. (2018): Sensitive screening method for determination of pyrethroids in chicken eggs and various meat samples by gas chromatography and electron capture detection. - Journal of Agricultural and Food Chemistry 66: 10267-10273.

[23] Okihashi, M., Kitagawa, Y., Obana, H., Tanaka, Y., Yamagishi, Y., Sugitate, K., Saito, K., Kubota, M., Kanai, M., Ueda, T. (2007): Rapid multiresidue method for the determination of more than 300 pesticide residues in food. - Food 1: 101-110.

[24] Paramasivam, M., Naik, R. H., Chandrasekaran, S. (2011): QuEChERS method for determination of some chlorinated hydrocarbon and synthetic pyrethroid residues in sheep meat by gas chromatography-electron capture detector. - Madras Agricultural Journal 98: 282-285.

[25] Park, J.-W., El-Aty, A. A., Lee, M.-H., Song, S.-O., Shim, J.-H. (2006): Residue analysis of organophosphorus and organochlorine pesticides in fatty matrices by gas chromatography coupled with electron-capture detection. - Zeitschrift für Naturforschung C 61: 341-346.

[26] Peng, G., He, Q., Lu, Y., Mmereki, D., Zhong, Z. (2016): Determination of organophosphorus pesticides and their major degradation product residues in food samples by HPLC-UV. - Environmental Science and Pollution Research 23: 1940919416.

[27] Sahu, R. K., Nelapati, K. (2018): Method validation for analysis of pesticide residues in Labeo rohita fish through GC-MS/MS. - Int J Chem Std 6: 1448-1452. 
[28] Schettgen, T., Dewes, P., Kraus, T. (2016): A method for the simultaneous quantification of eight metabolites of synthetic pyrethroids in urine of the general population using gas chromatography-tandem mass spectrometry. - Analytical and Bioanalytical Chemistry 408: 5467-5478.

[29] Stefanelli, P., Santilio, A., Cataldi, L., Dommarco, R. (2009): Multiresidue analysis of organochlorine and pyrethroid pesticides in ground beef meat by gas chromatographymass spectrometry. - Journal of Environmental Science and Health Part B 44: 350-356.

[30] Vitha, M. F. (2016): Chromatography: Principles and Instrumentation. - John Wiley \& Sons, Washington.

[31] Witczak, A. (2009): Effect of heat treatment on organochlorine pesticide residues in selected fish species. - Polish Journal of Food and Nutrition Sciences 59: 231-235.

[32] Yun-Sang, C., Hwang, K. E., Jeong, T. J., Kim, Y. B., Jeon, K. H., Kim, E. M., Sung, J. M., Kim, H. W., Kim, C. J. (2016): Comparative study on the effects of boiling, steaming, grilling, microwaving and superheated steaming on quality characteristics of marinated chicken steak. - Korean Journal for Food Science of Animal Resources 36: 1-7. 